\title{
Practical Operating Theatre Management: Measuring and Improving Performance and Patient Experience
}

\author{
Jaideep J. Pandit (Editor). Cambridge University Press; 2018; 198 pages. Online ISBN \\ $\mathbf{9 7 8 1 1 0 8 1 6 4 0 6 1}$
}

\author{
Orlaith McMahon, MB, BCh, BAO, FCAI $D$
}

Received: 10 December 2019/Revised: 20 December 2019/Accepted: 23 December 2019/Published online: 8 January 2020

(C) Canadian Anesthesiologists' Society 2020

Hospital systems worldwide are under pressure to improve their efficiency and productivity in the face of the evergrowing aging population and ever-increasing service use. In American media and politics, Canada's Medicare system has been the subject of much debate recently. Although widely regarded as an efficient, equitable system, the Canadian Institute of Health Information noted that, in 2019, "approximately $30 \%$ of patients who required a hip or knee replacement, or cataract surgery did not have their procedure done within the recommended wait times". ${ }^{1}$ In 2019, UK NHS hospital waiting times for elective surgery are reportedly at their worst-ever levels, with NHS England advising that patients for whom a procedure is cancelled should be offered "another binding date within 28 days" or their treatment funded at a date and hospital of the patient's choice. ${ }^{2}$ Such targets, although arguably necessary for patient safety and hospital efficiency, place significant pressure on operating room-related departments already running at maximum capacity.

If patient-centred care is indeed the priority for the hospital and operating room (or "theatre") management, measuring and improving performance and patient experience must be a key strategy when planning services. Although healthcare management courses and leadership seminars may address some of these issues, they can be expensive and inconvenient for medical staff working busy schedules. Pandit's book, Practical Operating Theatre Management: Measuring and Improving Performance and Patient Experience, succinctly tackles the theory of efficiency $v s$ productivity, the challenges of case scheduling and capacity planning,

O. McMahon, MB, BCh, BAO, FCAI ( $\square)$

Department of Anaesthesia, Nuffield Orthopaedic Centre,

Oxford University Hospitals NHS Foundation Trust, Oxford, UK and key concepts surrounding staffing, contracts, and theatre finances. Separate chapters are dedicated to each topic, with an introduction to the underlying concepts and theories and suggested practical approaches to address scheduling and planning issues. Equations, graphs, and plots are utilized to explain data to even the least mathematically minded reader.

The book primarily focuses on the "processes in operating theatres in an objective analysis" with the aim of finding "rational, data-led solutions". Chapters defining efficiency and productivity consider how, although utilization is commonly considered a measure of theatre efficiency, maximal utilization can be achieved only through overbooking. Resultant overruns are associated with negative financial and staffing consequences, with the perceived alternative being case cancellations - generally the result of multiple factors and therefore a poor measure of efficiency. Using practical examples, Pandit shows the fallacy of many current performance measures and encourages theatre teams to adopt a more objective approach to measuring efficiency and productivity. The chapter appendices explain the mathematical calculations of $\varepsilon$ (efficiency) and $\varphi$ (the productivity index) to facilitate objective analysis of theatre activity data.

Subsequent chapters in Practical Operating Theatre Management examine case scheduling and capacity planning, with Pandit arguing that case durations are indeed predictable overall. He thus advocates avoiding measurements of specialty-specific times and, instead, suggests measuring the entire case time, including anesthesia and surgery, to improve case planning and evaluate the overall team performance. He introduces a tool to assist with probabilistic case scheduling that includes quite advanced mathematical concepts, which 
might be difficult for some to understand but do not detract from the book's overall aims.

Staffing and contracts, though not discussed in depth, are acknowledged to underpin the many aspects of performance. Pandit reviews the differences between substantive and temporary contracts and the positive effect that reasonable contracts can have on staffing levels, professionalism, and overall staff goodwill. The subsequent chapter on theatre finances provides broad insight regarding the challenges faced by theatre management to balance costs and income - an area I believe is often overlooked by clinical staff. The idea of "profitable" vs "non-profitable" operations is discussed in the book along with the pros and cons of various funding systems, which differ widely across hospital systems.

Indeed, that operating theatres and services worldwide have markedly different approaches and management setups presents a challenge for this book to be relevant internationally. Although the author's primary experience is within the "typical UK NHS list", each chapter includes a discussion regarding the application of principles for a "typical UK private list" and "typical US list". Furthermore, four chapters are dedicated to discussion and application of the principles of theatre management by anesthetists in five healthcare systems around the world those in Japan, The Netherlands, Switzerland, Australia, and the United States. These international perspectives provide an excellent insight into the challenges encountered even in healthcare systems considered well financed and efficient. It also provides real examples of alternative approaches for readers to consider for improving performance in their own hospitals.
Pandit's penultimate chapter provides a synopsis of recommended safe practices for theatres to adopt, followed by a personal overview - i.e., an excellent summary of the book's key points from the author's own perspective and experience. Overall, Practical Operating Theatre Management: Measuring and Improving Performance and Patient Experience delivers on both content and readability supported by data-driven metrics, making it a useful resource for clinical staff, theatre managers, and hospital management alike. I highly recommended it for future healthcare management course curricula.

Conflicts of interest None.

Funding statement None.

Editorial responsibility This submission was handled by Dr. Hilary P. Grocott, Editor-in-Chief, Canadian Journal of Anesthesia.

\section{References}

1. Canadian Institute of Health Information. 2019: Wait times for priority procedures in Canada, 2019. Available from URL: https:// www.cihi.ca/en/wait-times-for-priority-procedures-in-canada (accessed December 2019)

2. Public Health England; Department of Health \& Social Care. Handbook to the NHS Constitution for England. Updated 28 October 2019. Available from URL: https://www.gov.uk/ government/publications/supplements-to-the-nhs-constitution-forengland/the-handbook-to-the-nhs-constitution-for-england (accessed December 2019).

Publisher's Note Springer Nature remains neutral with regard to jurisdictional claims in published maps and institutional affiliations. 